\title{
Differences in dietary intake during chemotherapy in breast cancer patients compared to women without cancer
}

\author{
Y. C. de Vries ${ }^{1,2}$ • M. M. G. A. van den Berg ${ }^{1}$ - J. H. M. de Vries ${ }^{1}$ - S. Boesveldt ${ }^{1}$ \\ J. Th. C. M. de Kruif ${ }^{3} \cdot$ N. Buist ${ }^{4}$ - A. Haringhuizen ${ }^{5}$ M. Los $^{6}$ • D. W. Sommeijer ${ }^{7,8}$. \\ J. H. N. Timmer-Bonte ${ }^{9}$ - H. W. M. van Laarhoven ${ }^{7}$ - M. Visser ${ }^{3}$ - E. Kampman ${ }^{1}$. \\ R. M. Winkels ${ }^{1}$
}

Received: 8 December 2016 / Accepted: 6 March 2017 /Published online: 16 March 2017

(C) The Author(s) 2017. This article is published with open access at Springerlink.com

\begin{abstract}
Purpose Breast cancer patients receiving chemotherapy often experience symptoms such as nausea, vomiting and loss of appetite that potentially affect dietary habits. This study assessed the intake of energy, macronutrients and food groups before and during chemotherapy in breast cancer patients compared with women without cancer, and determined the association between symptoms and energy and macronutrient intake. Methods This study included 117 newly diagnosed breast cancer patients scheduled for chemotherapy and 88 women without cancer. Habitual intake before chemotherapy was assessed with a food frequency questionnaire. Two 24-h
\end{abstract}

Y. C. de Vries and M. M. G. A. van den Berg shared first authorship

Electronic supplementary material The online version of this article (doi:10.1007/s00520-017-3668-x) contains supplementary material, which is available to authorized users.

R. M. Winkels

Renate.winkels@wur.nl

1 Division of Human Nutrition, Wageningen University, Wageningen, The Netherlands

2 Top Institute Food and Nutrition, Wageningen, The Netherlands

3 Department of Health Sciences, VU University Amsterdam, Amsterdam, The Netherlands

4 Amphia Ziekenhuis, Breda, The Netherlands

5 Ziekenhuis Gelderse Vallei, Ede, The Netherlands

6 Antonius Ziekenhuis, Nieuwegein/Utrecht, The Netherlands

7 Department of Oncology, Academic Medical Center, Amsterdam, The Netherlands

8 Flevoziekenhuis, Almere, The Netherlands

9 Department of Oncology, Alexander Monro Ziekenhuis, Bithoven, The Netherlands dietary recalls were completed on random days for each participant during the whole chemotherapy treatment for patients and within 6 months after recruitment for women without cancer. Shortly, after the dietary recall, participants filled out questionnaires on symptoms.

Results Before chemotherapy, habitual energy and macronutrient intake was similar for breast cancer patients and women without cancer. During chemotherapy, breast cancer patients reported a significantly lower total energy, fat, protein and alcohol intake than women without cancer, as shown by a lower intake of pastry and biscuits, cheese, legumes and meat products. A decline in subjective taste perception, appetite and hunger and experiencing a dry mouth, difficulty chewing, lack of energy and nausea were associated with a lower energy intake. Conclusions Symptoms induced by chemotherapy are associated with lower dietary intake and manifested by a lower intake of specific food groups. To ensure an optimal dietary intake during chemotherapy, it is important to monitor nutritional status and symptom burden during chemotherapy in breast cancer patients.

Keywords Breast cancer - Chemotherapy · Dietary intake · Macronutrients · Side effect

\section{Introduction}

The majority of women with breast cancer is treated with chemotherapy [1]. Treatment with cytotoxic drugs is often accompanied with symptoms such as nausea, vomiting, loss of appetite, dry mouth and changes in taste or smell perception. These symptoms can be very disturbing and can significantly impact quality of life $[2,3]$. In types of cancer where the gastrointestinal tract is affected, such as head and neck cancer, the impact of these symptoms on dietary intake and nutritional status is 
well established [4, 5]. However, for breast cancer patients, the experience of symptoms during cancer treatment may differ and the extent to which symptoms specifically affect dietary intake in breast cancer patients is less clear.

Previous studies that investigated whether dietary intake changed during chemotherapy in breast cancer patients are inconsistent in their findings. They either showed increases [6], decreases $[7,8]$ or no changes [9-11] in energy intake during chemotherapy, possibly because different studies used different methods and different time points during the course of chemotherapy to assess dietary intake. Most studies in breast cancer patients assessed dietary intake only in the week prior to a next chemotherapy cycle, while dietary intake is suggested to vary during a cycle [12]. Most importantly, earlier studies did not compare dietary intake in breast cancer patients to a comparable group of women without breast cancer, limiting the possibility to assess whether changes in intake deviate from normal fluctuations in intake over time. Additionally, most studies are limited by only focussing on energy and macronutrient intake and not on food items or food groups. Thereby, it is unknown whether changes in dietary intake during chemotherapy are due to changes in intake of specific food groups.

There are studies that suggest that breast cancer patients gain weight during and after chemotherapy, which may be associated with an increased risk of comorbidities like cardiovascular disease and diabetes [13, 14]. Therefore, it is important to give breast cancer patients well-grounded advice on their lifestyle and dietary habits before, during and after treatment. Especially, since breast cancer patients have expressed a need for dietary support during treatment with chemotherapy [15]; unmet supportive care needs in cancer patients are highest during treatment [16]. However, in order to give specific dietary advice, it is important to first know what the actual change in dietary intake of breast cancer patients is and which symptoms are associated with dietary changes during chemotherapy.

Therefore, the aim of this observational study was to assess the intake of energy, macronutrients and food groups before and during chemotherapy in breast cancer patients in comparison with a group of women without cancer and to determine the association between the experience of specific symptoms and energy and macronutrient intake.

\section{Materials and methods}

\section{Participants}

This study is part of an ongoing observational multi-centre study among breast cancer patients during chemotherapy and a comparison group of women of similar age without cancer (COBRA-study). Women with newly diagnosed, incident, stage I-IIIB, operable breast cancer, scheduled for 2 nd or 3 rd generation chemotherapy were compared with women without cancer of similar age (range within 2 years). Eligible patients were recruited by the staff of 11 participating hospitals prior to commencement of chemotherapy. The comparison group was recruited via the women with breast cancer, who were asked to distribute information about the study to female friends, acquaintances and colleagues. This approach was chosen to maximize the comparability of groups with respect to possible confounding factors, and thus to minimize the risk that other factors than chemotherapy influenced our findings on dietary intake. Women without cancer contacted the researchers if they were interested in participating in the study. All study participants needed to be at least 18 years old and be able to communicate in Dutch. Exclusion criteria were history of cancer, previous treatment with chemotherapy, pregnancy or the intention to get pregnant during the study period, dementia or other mental conditions that made it impossible to comply with the study procedures. The protocol was approved by the Medical Ethical Committee of Wageningen University (ABR NL40666.081.12). All participants provided written informed consent before enrolment.

\section{Measurements}

\section{Dietary intake}

Upon recruitment, all participants filled out a food frequency questionnaire (FFQ) to assess habitual intake before chemotherapy (patient group) or start of the study (comparison group) $[17,18]$. During chemotherapy, actual dietary intake was assessed using two telephone-based 24-h dietary recalls, because of the expected high day to day variation during chemotherapy. The recalls were planned on two random days during chemotherapy, during all weeks within a chemotherapy cycle and over all chemotherapy cycles administered. Recalls were planned between the day of the first chemotherapy infusion and 3 weeks after the last chemotherapy infusion. Women in the comparison group also completed two recalls, which were planned on two random days within 6 months after recruitment. This was a comparable time-frame, as current oncological guidelines for chemotherapy for breast cancer in the Netherlands encompass schemes which mostly take 4.5 to 6 months to complete. Randomization of the recall days was done for each participant separately. The two recalls were scheduled at least 7 days apart. If it was not possible to complete the recall on the scheduled day, a new day was planned randomly within 2 weeks. The 24-h recalls were performed using a standardized protocol and conducted by trained dietitians. The recalls were at least 1 week apart and were conducted both on week and weekend days. Dietary recall data were coded and entered, after which the intake of total energy, protein, carbohydrate, fat, alcohol and fibre were calculated in the computation module of Compl-eat ${ }^{\mathrm{TM}}$ using the Dutch food composition table 2013 [19]. A data check was performed 
by the dietitians. The highest and lowest ten values for energy, macronutrients, and fruit and vegetables intake were checked for errors in coding or amounts. Food items were grouped into food groups for both the food frequency questionnaire and 24$\mathrm{h}$ dietary recall [19]. These food groups were bread; cereal and cereal products; fruit; vegetables; legumes; nuts, seeds and snacks; soups; soy products and vegetarian products; pastry and biscuits; sugar, candy sweet toppings and sweet sauces; milk and dairy products; cheese; eggs; meat and meat products; and fish.

\section{Symptoms}

After being called for each 24-h recall, participants were instructed to fill out questionnaires on sensory perception and experienced symptoms. The Appetite, Hunger feelings and Sensory Perception (AHSP) questionnaire was used to assess self-judgement of taste, smell and appetite [20]. The questionnaire consisted of 29 questions answered on a 5 point Likert scale, concerning four categories: taste ( 8 items, score range 8-40), smell (6 items, range 6-30), appetite (6 items, range 6-30) and hunger (9 items, range 9-45). An example of a question for taste was as follows: In former days the taste of food was: 1 . much better than nowadays, 2 . better than nowadays, 3 . the same as nowadays, 4 . worse than nowadays, 5 . much worse than nowadays. For the patient group, 'former days' was referenced as the situation before chemotherapy and for the comparison group as the situation 1 year ago. A higher score corresponds to a more positive judgement about current taste and smell perception, appetite and hunger. The severity of 13 additional symptoms was assessed: pain, dry mouth, feeling depressed, thick saliva, diarrhoea, sore mouth, lack of energy, nausea, difficulty chewing, difficulty swallowing, anxiety, constipation and vomiting. For each symptom, the question was asked as follows: 'How often have you experienced this symptom during the past three days?', scored on a 5 point Likert scale, ranging from $1=$ 'not at all' to $5=$ 'a lot'. If participants did not answer the symptoms questionnaires within 3 days after completing the 24-h dietary recall, we did not include their data in the analyses. In total, we collected $n=274$ recalls from patients and $n=205$ recalls from women without breast cancer. A number of $n=205$ recalls from breast cancer patients and $n=152$ recalls from women without cancer were used in the analyses in this paper. Excluding participants who did not complete the questionnaires within 3 days from analysis did not significantly influence the results on energy and macronutrient intake.

\section{Demographics and medical information}

All participants filled out a baseline questionnaire for demographic information, including age, smoking status and educational level. Information on stage of cancer at diagnosis and treatment were obtained from reviewing patients' medical records. Dates of chemotherapy cycles were compared with the dates of the 24-h recalls to classify the recalls into the week within a chemotherapy cycle and to the number of cycles that was administered at the date of the 24-h recalls.

\section{Data analysis}

Population characteristics were described as medians with interquartile range (IQR) or percentages of the patient and comparison group separately. To assess differences in the population characteristics between the groups, the Mann-Witney $U$ test was used for continuous data and the chi-square test for categorical data. Differences in dietary intake at study onset (FFQ) between the women with and without breast cancer were analysed with linear regression. Mixed model analysis was used to assess differences in energy, macronutrient and food group intake between the patient and comparison group. For the analysis of differences in dietary intake within a chemotherapy cycle for patients receiving a three weekly scheme of chemotherapy, recalls were classified according to the week within a chemotherapy cycle a $24-\mathrm{h}$ recall was administered (week 1, week 2 or week 3 ) and to the number of cycles administered. Patients with weekly chemotherapy cycles were excluded from this analysis $(n=22$ recalls). Mixed models were also used to assess the association between symptoms and energy intake. Interactions between each symptom and group (patient and comparison group) were evaluated to test whether associations between symptoms and energy intake were different between the two groups. For significant interactions ( $p$ value $\leq 0.1$ ), stratified results for patients and the comparison group are shown. For symptoms with a significant association with energy intake, data was also analysed for the macronutrients protein, carbohydrates and fat. Covariates considered as potential confounders were included in the regression and mixed models analyses based on the literature and change of regression coefficient. Variables that changed the regression coefficient $\geq 10 \%$ in the adjusted model compared to the crude model were included in the final model. Final regression and mixed models analyses were adjusted for age at inclusion, BMI at inclusion, education level and smoking status at inclusion. Statistical analyses were performed using SPSS, version 21 (SPSS Inc. Chicago, IL). A $p$ value $<0.05$ was considered as statistically significant.

\section{Results}

\section{Patient characteristics}

Data were collected for 117 breast cancer patients and 88 women in the comparison group, see Table 1. BMI was higher in women with breast cancer than in women without breast 
Table 1 Demographic and clinical characteristics of the patient and comparison group included in the study

\begin{tabular}{|c|c|c|}
\hline Characteristic & Comparison group $(n=88)$ & Patient group $(n=117)$ \\
\hline \multicolumn{3}{|l|}{ Demographics } \\
\hline Age, years (median, IQR) & $53.5(46.1-60.9)$ & $51.0(46.8-55.3)$ \\
\hline \multicolumn{3}{|l|}{ Education level $(n, \%)^{*}$} \\
\hline Low & $4(4.5)$ & $12(10.4)$ \\
\hline Medium & $18(20.5)$ & $35(30.4)$ \\
\hline High & $66(75.0)$ & $68(59.1)$ \\
\hline \multicolumn{3}{|l|}{ Lifestyle } \\
\hline BMI, $\mathrm{kg} / \mathrm{m}^{2}$ (median, IQR)* & $23.8(22.1-26.7)$ & $25.2(22.3-28.4)$ \\
\hline \multicolumn{3}{|l|}{ Smoking status $(n, \%)$} \\
\hline Current & $9(10.2)$ & $21(18.1)$ \\
\hline Former & $40(45.5)$ & $49(42.2)$ \\
\hline Never & $39(44.3)$ & $46(39.7)$ \\
\hline \multicolumn{3}{|l|}{ Medical profile } \\
\hline \multicolumn{3}{|l|}{ Tumour stage $(n, \%)$} \\
\hline I & & $25(21.4)$ \\
\hline II & & $70(59.8)$ \\
\hline III & & $22(18.8)$ \\
\hline Adjuvant chemotherapy $(n, \%)$ & & $68(58.1)$ \\
\hline Neo adjuvant chemotherapy $(n, \%)$ & & 49 (41.9) \\
\hline \multicolumn{3}{|l|}{ Chemotherapy regimen $(n, \%)$} \\
\hline Taxanes only & & $4(3.4)$ \\
\hline Anthracyclines only & & $4(3.4)$ \\
\hline Taxanes + anthracyclines & & $109(93.2)$ \\
\hline
\end{tabular}

cancer. In the patient group, fewer women had a high educational level than in the comparison group. There were no differences for age, smoking status and menopausal status between the groups. The majority of the breast cancer patients had a stage 2 tumour and received adjuvant chemotherapy combining taxanes and anthracyclines.

\section{Dietary intake at study onset}

At study onset, mean energy, protein, fat and carbohydrate intakes were similar between the patient and comparison group as assessed with a food frequency questionnaire (Table 2). Women with breast cancer reported to consume less alcohol than women in the comparison group. Intake for the various food groups was similar between the two groups, with the exception of cheese intake, which was slightly higher in breast cancer patients compared to the women without cancer.

\section{Dietary intake during chemotherapy}

In total, 357 recalls were collected, 205 in the patient group and 152 in the comparison group. During chemotherapy, breast cancer patients had a significantly lower energy intake than the women without cancer as assessed with 24-h dietary recalls, $1779 \pm 56$ vs $1993 \pm 68 \mathrm{kcal}$ (Table 3). Breast cancer patients reported a significant lower absolute intake of protein, fat, and alcohol, but not of carbohydrates and fibre than women without cancer. Expressed as energy percentages, during chemotherapy women with breast cancer consumed relatively more energy from carbohydrates and less energy from alcohol compared to women without cancer.

During chemotherapy, women with breast cancer consumed less energy from the food groups legumes, pastry and biscuits, cheese and meat than the women without cancer (Table 4). The intake of other food groups bread; cereal and cereal products; fruit; vegetables; nuts, seeds and snacks; soups; soy and vegetarian products; sugar, sweets, sweet toppings and sweet sauces; milk and dairy products; cheese; eggs; and fish was similar between breast cancer patients during chemotherapy and women without cancer. Results expressed in grammes per day can be found in Online Resource 1. The main sources of total protein, fat and carbohydrate intake were similar for the patient and the comparison group. The main sources of protein intake were meat, bread and milk and dairy 
Table 2 Habitual intake of energy, macronutrients and food groups for the patient and comparison group (mean $\pm \mathrm{SE}$ ) and differences in intake between the groups at study onset, assessed by a food frequency questionnaire

\begin{tabular}{|c|c|c|c|}
\hline & \multicolumn{3}{|c|}{ Intake in Kcal $($ mean $\pm \mathrm{SE})$} \\
\hline & $\begin{array}{l}\text { Comparison group } \\
\qquad(N=88)\end{array}$ & $\begin{array}{l}\text { Patient group } \\
\quad(N=114)\end{array}$ & $\begin{array}{r}\text { Difference }^{a} \\
(95 \% \mathrm{CI})\end{array}$ \\
\hline Energy & $2069 \pm 69.2$ & $2070 \pm 59.7$ & $\begin{array}{l}1 \\
(-181 ; 184)\end{array}$ \\
\hline Protein & $318 \pm 10.1$ & $315 \pm 8.7$ & $\begin{array}{l}-3 \\
(-30 ; 24)\end{array}$ \\
\hline Carbohydrate & $859 \pm 31.3$ & $870 \pm 27.0$ & $\begin{array}{l}11 \\
(-71 ; 93)\end{array}$ \\
\hline Fat & $761 \pm 32.3$ & $779 \pm 27.8$ & $\begin{array}{l}18 \\
(-67 ; 103)\end{array}$ \\
\hline Alcohol* & $75 \pm 7.5$ & $51 \pm 6.5$ & $\begin{array}{l}-24 \\
(-44 ;-4)\end{array}$ \\
\hline Fibre & $46 \pm 1.6$ & $45 \pm 1.4$ & $\begin{array}{l}-1 \\
(-5 ; 3)\end{array}$ \\
\hline \multicolumn{4}{|l|}{ Food groups } \\
\hline Bread & $256 \pm 16.7$ & $256 \pm 14.4$ & $\begin{array}{l}0 \\
(-44 ; 44)\end{array}$ \\
\hline Cereal and cereal products & $139 \pm 10.9$ & $131 \pm 9.4$ & $\begin{array}{l}-8 \\
(-37 ; 21)\end{array}$ \\
\hline Fruit & $134 \pm 8.3$ & $118 \pm 7.2$ & $\begin{array}{l}-16 \\
(-37 ; 7)\end{array}$ \\
\hline Vegetables & $50 \pm 3.5$ & $53 \pm 3.0$ & $\begin{array}{l}3 \\
(-6 ; 12)\end{array}$ \\
\hline Legumes & $10 \pm 1.6$ & $11 \pm 1.4$ & $\begin{array}{l}1 \\
(-4 ; 5)\end{array}$ \\
\hline Nuts, seeds and snacks & $168 \pm 15.7$ & $146 \pm 13.5$ & $\begin{array}{l}-22 \\
(-63 ; 19)\end{array}$ \\
\hline Soups & $24 \pm 3.3$ & $22 \pm 2.8$ & $\begin{array}{l}-2 \\
(-11 ; 6)\end{array}$ \\
\hline Soy products and vegetarian products & $18 \pm 5.3$ & $16 \pm 4.5$ & $\begin{array}{l}-2 \\
(-15 ; 12)\end{array}$ \\
\hline Pastry and biscuits & $119 \pm 11.3$ & $136 \pm 9.7$ & $\begin{array}{l}17 \\
(-13 ; 47)\end{array}$ \\
\hline Sugar, candy, sweet toppings and sweet sauces & $110 \pm 10.6$ & $120 \pm 9.2$ & $\begin{array}{l}10 \\
(-18 ; 38)\end{array}$ \\
\hline Milk and dairy products & $195 \pm 13.9$ & $173 \pm 12.0$ & $\begin{array}{l}-22 \\
(-58 ; 15)\end{array}$ \\
\hline Cheese* & $105 \pm 13.8$ & $145 \pm 11.9$ & $\begin{array}{l}40 \\
(3 ; 76)\end{array}$ \\
\hline Eggs & $25 \pm 2.6$ & $24 \pm 2.3$ & $\begin{array}{l}-1 \\
(-8 ; 6)\end{array}$ \\
\hline Meat, meat products and poultry & $153 \pm 9.3$ & $159 \pm 8.0$ & $\begin{array}{l}6 \\
(-19 ; 30)\end{array}$ \\
\hline Fish & $36 \pm 3.1$ & $29 \pm 2.7$ & $\begin{array}{l}-7 \\
(-15 ; 1)\end{array}$ \\
\hline
\end{tabular}

${ }^{a}$ Adjusted for age, BMI, education level, smoking status

$* p<0.05$ 
Table 3 Energy and macronutrient intake in kcal and energy percentages (en\%) for the breast cancer patients during chemotherapy and comparison group during follow up (mean $\pm \mathrm{SE}$ ) and the differences in intake between the groups

\begin{tabular}{|c|c|c|c|c|c|c|c|}
\hline & \multicolumn{2}{|c|}{ Intake in kcal* $($ mean $\pm \mathrm{SE})$} & \multirow[t]{2}{*}{ Difference $^{\mathrm{a}}(95 \% \mathrm{CI})$} & & \multicolumn{2}{|c|}{ Intake in en $\% *($ mean $\pm \mathrm{SE})$} & \multirow{2}{*}{$\begin{array}{l}\text { Difference }^{\mathrm{a}} \\
(95 \% \mathrm{CI})\end{array}$} \\
\hline & Comparison group & Patient group & & & Comparison group & Patient group & \\
\hline Energy* & $1993 \pm 68.3$ & $1779 \pm 55.7$ & $\begin{array}{l}-214 \\
(-353 ;-76)\end{array}$ & Energy & & & \\
\hline Protein* & $313 \pm 10.7$ & $270 \pm 8.8$ & $\begin{array}{l}-43 \\
(-64 ;-21)\end{array}$ & Protein & $16.3 \pm 0.45$ & $15.5 \pm 0.37$ & $\begin{array}{l}-0.8 \\
(-1.6 ; 0.2)\end{array}$ \\
\hline Carbohydrate & $844 \pm 34.4$ & $815 \pm 28.0$ & $\begin{array}{l}-29 \\
(-99 ; 41)\end{array}$ & Carbohydrate* & $41.9 \pm 1.0$ & $46.2 \pm 0.82$ & $\begin{array}{l}4.3 \\
(2.2 ; 6.3)\end{array}$ \\
\hline Fat* & $734 \pm 32.0$ & $633 \pm 26.1$ & $\begin{array}{l}-101 \\
(-166 ;-37)\end{array}$ & Fat & $36.6 \pm 0.85$ & $35.0 \pm 0.70$ & $\begin{array}{l}-1.6 \\
(-3.4: 0.1)\end{array}$ \\
\hline Alcohol* & $54 \pm 9.4$ & $17 \pm 7.7$ & $\begin{array}{l}-37 \\
(-57 ;-19)\end{array}$ & Alcohol* & $2.8 \pm 0.47$ & $0.8 \pm 0.38$ & $\begin{array}{l}-2.0 \\
(-2.9 ;-1.0)\end{array}$ \\
\hline Dietary fibre & $38 \pm 1.8$ & $35 \pm 1.4$ & $\begin{array}{l}-3 \\
(-7 ; 1)\end{array}$ & Dietary fibre & $2.0 \pm 0.09$ & $2.0 \pm 0.07$ & $\begin{array}{l}0.0 \\
(-0.1 ; 0.2)\end{array}$ \\
\hline
\end{tabular}

${ }^{\text {a }}$ Adjusted for age, BMI, education level, smoking status

$* p<0.05$

products. For fat, the main sources were fats, oils and savoury sauces, cheese and meat. Carbohydrates came mostly from the food groups bread, alcoholic and non-alcoholic drinks, milk and dairy products and fruit.

Dietary intake in the patient group was lower compared to the women without cancer in all three weeks after chemotherapy was administered and was lowest in each first week. However, there were no statistically significant differences in energy and macronutrient intake between the first, second and third week within a chemotherapy (Online Resource 2). In addition, there was no association between dietary intake and the number of chemotherapy cycles administered.

\section{Symptoms}

During chemotherapy, the patient group scored significantly lower on their self-reported taste, smell, appetite and hunger, compared to the women without cancer (Table 5). Furthermore, breast cancer patients undergoing chemotherapy experienced more often anxiety, dry mouth, constipation, feeling depressed, thick saliva, diarrhoea, sore mouth, lack of energy, nausea, difficulty chewing and difficulty swallowing than women in the comparison group (Table 6). Scores were not different for the symptoms pain and vomiting between the patient and the comparison group. Only three women with breast cancer and one woman without breast cancer reported vomiting as a symptom they experienced that day; therefore, vomiting was not analysed for its association with energy intake.

\section{Symptoms and dietary intake}

A higher self-judgement of taste perception, better appetite and more hunger were significantly associated with a higher energy intake (Table 5). Self-judgement of smell was not significantly associated with energy intake.

Having a dry mouth, lack of energy, nausea and having difficulty chewing were significantly associated with a lower energy intake (Table 6). The associations between anxiety and energy intake and between constipation and energy intake were different for the patient and the comparison group (interaction anxiety $p=0.02$, constipation $p=0.03$ ); anxiety was not associated with energy intake in breast cancer patients, while it was associated with a lower energy intake in the comparison group. Constipation was associated with a higher energy intake in the patient group and with a lower energy intake in the comparison group, but these associations were not statistically significant (Table 6).

For the symptoms that were significantly associated with energy intake, we additionally assessed whether those symptoms were associated with protein, carbohydrate and fat intake. Briefly, those associations were in the same direction as how the intake of macronutrients differed during chemotherapy between the patients and the comparison group; symptoms were associated with a lower protein and fat intake and not associated with the intake of carbohydrates (Online Resource 3).

\section{Discussion}

To date, this is the largest study that examined energy, macronutrient and food group intake in breast cancer patients during chemotherapy compared to a group of women without cancer. We showed that breast cancer patients had a significantly lower energy intake during chemotherapy compared with a group of women without cancer. Since habitual intake of breast cancer patients before start of chemotherapy was comparable to 
Table 4 Intake per food group for the breast cancer patients during chemotherapy and comparison group during follow up (mean \pm SE) and the differences in intake between the groups in kcal

\begin{tabular}{|c|c|c|c|}
\hline & \multicolumn{2}{|c|}{ Intake in kcal* $($ mean $\pm \mathrm{SE})$} & \multirow[b]{2}{*}{$\begin{array}{l}\text { Difference } \\
(95 \% \mathrm{CI})^{\mathrm{a}}\end{array}$} \\
\hline & Comparison group & Patient group & \\
\hline Bread & $332 \pm 39.5$ & $291 \pm 37.2$ & $\begin{array}{l}-41 \\
(-81 ; 2)\end{array}$ \\
\hline Cereal and cereal products & $68 \pm 29.4$ & $67 \pm 27.7$ & $\begin{array}{l}-1 \\
(-32 ; 31)\end{array}$ \\
\hline Fruit & $98 \pm 26.5$ & $86 \pm 24.9$ & $\begin{array}{l}-121 \\
(-40 ; 16)\end{array}$ \\
\hline Vegetables & $41 \pm 9.4$ & $33 \pm 8.9$ & $\begin{array}{l}-8 \\
(-17 ; 3)\end{array}$ \\
\hline Legumes* & $136 \pm 39.2$ & $83 \pm 36.9$ & $\begin{array}{l}-53 \\
(-95 ;-12)\end{array}$ \\
\hline Nuts seeds and snacks & $7 \pm 11.8$ & $9 \pm 11.1$ & $\begin{array}{l}2 \\
(-11 ; 14)\end{array}$ \\
\hline Soups & $35 \pm 28.5$ & $22 \pm 26.8$ & $\begin{array}{l}-13 \\
(-43 ; 18)\end{array}$ \\
\hline Soy products and vegetarian products & $29 \pm 14.9$ & $31 \pm 14.0$ & $\begin{array}{l}2 \\
(-14 ; 18)\end{array}$ \\
\hline Pastry and biscuits* & $131 \pm 36.6$ & $84 \pm 34.4$ & $\begin{array}{l}-47 \\
(-86 ;-8)\end{array}$ \\
\hline Sugar, candy, sweet toppings and sweet sauces & $90 \pm 28.7$ & $86 \pm 27.0$ & $\begin{array}{l}-4 \\
(-34 ; 26)\end{array}$ \\
\hline Milk and dairy products & $164 \pm 36.6$ & $170 \pm 34.5$ & $\begin{array}{l}6 \\
(-33 ; 44)\end{array}$ \\
\hline Cheese* & $140 \pm 22.4$ & $112 \pm 21.1$ & $\begin{array}{l}-28 \\
(-52 ;-4)\end{array}$ \\
\hline Eggs & $35 \pm 9.1$ & $39 \pm 8.6$ & $\begin{array}{l}4 \\
(-6 ; 14)\end{array}$ \\
\hline Meat, meat products and poultry* & $190 \pm 31.8$ & $150 \pm 29.9$ & $\begin{array}{l}-40 \\
(-74 ;-6)\end{array}$ \\
\hline Fish & $25 \pm 22.3$ & $42 \pm 21.0$ & $\begin{array}{l}17 \\
(-8 ; 40)\end{array}$ \\
\hline
\end{tabular}

${ }^{\text {a }}$ Adjusted for age, BMI, education level, smoking status $* p<0.05$

the women without cancer in our study, we can assume that the differences found between the groups were mostly due to the consequences of chemotherapy. These findings are in accordance with two other studies that observed a lower energy intake in breast cancer patients during chemotherapy compared to before chemotherapy [7, 8]. Only one previous study, published in 1987, suggested a higher dietary intake during chemotherapy in breast cancer patients compared with controls [6]. However, that study had a control group which already had a lower intake at baseline, limiting the reliability of those conclusions.

The lower energy intake that we observed during chemotherapy was not caused by a lower intake of all macronutrients.
The intakes of fat, protein and alcohol were lower during chemotherapy in breast cancer patients than in women without cancer, while intakes of carbohydrates and dietary fibre were similar. The lower protein and fat intake can be explained by the food groups that were consumed less during chemotherapy; meat and cheese are mostly high in protein and fat, and may thereby partially account for the different intakes of macronutrients. Habitual alcohol intake was lower in breast cancer patients before chemotherapy than women without cancer, and the intake remained lower during chemotherapy. As alcohol is a known risk factor for breast cancer [21], a higher or comparable alcohol intake could be expected in the patient group compared to the women without cancer. Possibly, breast cancer patients 
Table 5 Taste, smell, appetite and hunger scores from AHSP questionnaire for the breast cancer patients during chemotherapy and comparison group during follow up (mean \pm SE) and the association of AHSP categories with energy intake (kcal). Higher scores indicate a more positive self-judgement on the categories of the questionnaire. $\beta$ for energy intake is the difference in energy intake (kcal) per 1 unit higher score within ASHP category

\begin{tabular}{|c|c|c|c|c|c|}
\hline \multirow[t]{2}{*}{ Category } & \multirow[t]{2}{*}{ Range } & \multicolumn{2}{|l|}{$\begin{array}{l}\text { Score questionnaire } \\
(\text { mean } \pm \mathrm{SE})\end{array}$} & \multirow[b]{2}{*}{ Difference } & \multirow{2}{*}{ 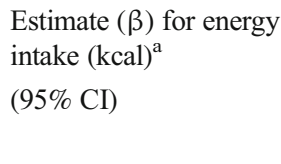 } \\
\hline & & Comparison group & Patient group & & \\
\hline Taste & $8-40$ & $30.9 \pm 0.71$ & $22.0 \pm 0.57$ & $\begin{array}{l}-8.9^{*} \\
(-10.4 ;-7.5)\end{array}$ & $\begin{array}{c}16.4^{*} \\
(7.0 ; 25.8)\end{array}$ \\
\hline Smell & $6-30$ & $23.3 \pm 0.42$ & $20.6 \pm 0.42$ & $\begin{array}{l}-2.7 * \\
(-3.7 ;-1.8)\end{array}$ & $\begin{array}{c}11.9 \\
(-5.0 ; 28.7)\end{array}$ \\
\hline Appetite & $6-30$ & $24.7 \pm 0.40$ & $18.7 \pm 0.50$ & $\begin{array}{l}-6.0^{*} \\
(-7.0 ;-5.0)\end{array}$ & $\begin{array}{c}26.5^{*} \\
(14.4 ; 38.5)\end{array}$ \\
\hline Hunger & $9-45$ & $38.3 \pm 0.70$ & $32.5 \pm 0.70$ & $\begin{array}{l}-5.8^{*} \\
(-7.4 ;-4.3)\end{array}$ & $\begin{array}{c}24.5^{*} \\
(15.1 ; 33.9)\end{array}$ \\
\hline
\end{tabular}

${ }^{a}$ Adjusted for age, BMI, education level, smoking status

This should also be in table 6 underreported their alcohol intake due to social desirability bias. However, it is also possible that breast cancer patients changed their dietary habits due do cancer diagnosis. Cancer diagnosis has been referred to as a 'teachable moment' for lifestyle changes and may motivate patients to change their dietary habits [22].

Patients in our study experienced a variety of symptoms during chemotherapy, but not all were associated with energy intake. Specifically, the symptoms of lower self-reported taste, lower appetite, less hunger, dry mouth, lack of energy, nausea and difficulty chewing were associated with a lower energy intake. These symptoms are known to limit the enjoyment of eating as they make eating more difficult. It is thus not surprising that they have been previously related to a lower energy intake [4, 23]. Interestingly, self-judgement of taste was significantly associated with energy intake, but selfjudgement of smell was not, while smell function is generally recognized as an important factor for food intake [24]. We must consider that humans are generally not well able to rate their own smell sensitivity [25]. Therefore, we cannot exclude that reduced smell function influences energy intake. The experience of symptoms does not only have an effect on dietary intake, symptoms also negatively impact quality of life [26]. Therefore, it is important to monitor symptoms during chemotherapy and to treat symptoms where possible. Furthermore, given the associations of symptoms with dietary intake, it is important to monitor nutritional status to ensure an adequate intake of energy and nutrients during chemotherapy.

In addition to experienced symptoms, changed preferences for foods may be related to the changed food choices we observed during chemotherapy. Aversions for meat are commonly reported during chemotherapy $[27,28]$ and may thereby underlie the lower intake of this food group that we observed in breast cancer patients during chemotherapy compared to the women without cancer. However, research on food preferences during chemotherapy is mostly anecdotal and scarcely measured quantitatively and should be taken into account in future studies.

Studies suggest that breast cancer patients gain weight during and after chemotherapy [13, 14]. To date, it is not clear which factors underlie these weight changes. However, our study does not suggest nutritional intake as a contributing factor for this weight gain, as we observe a decreased energy intake of patients during chemotherapy. However, breast cancer patients may have a lower energy requirement, as physical activity may be lower $[9,29]$. Additionally, reductions in resting energy expenditure have been reported during and after chemotherapy $[13,14]$. Therefore, studies assessing weight change during chemotherapy should take changes in dietary intake, physical activity and resting energy expenditure into account to assess the contribution of these factors on weight change.

Previous studies investigating dietary intake during chemotherapy in breast cancer patients were heterogeneous in the time points dietary intake was assessed. Mostly, it was assessed the week before a next cycle would be administered. In our study, we deliberately chose to assess dietary intake at random days during the full cycle of chemotherapy, thereby capturing the full variation in dietary intake over chemotherapy. Although there were no significant differences between the weeks within chemotherapy cycles, there was variation within the weeks; dietary intake was lowest in the first week after a cycle was administered. This renders the importance to take into account all weeks within chemotherapy cycles to give a correct representation of dietary intake during chemotherapy.

It cannot be excluded that differential reporting of dietary intake between patients and the comparison group influenced the results of our study. Differential reporting may be influenced by differences in BMI [30]. BMI was slightly higher in 
Table 6 Results of the symptom questionnaire for the breast cancer patients during chemotherapy and comparison group during follow up (mean \pm SE) and the association between symptoms and energy intake (kcal). Symptom severity was assessed on a 5 point Likert scale ( $1=$ not at all, $5=a$ lot). $\beta$ for energy intake indicates the difference in energy intake (kcal) per 1 unit higher score in the symptom

\begin{tabular}{|c|c|c|c|c|}
\hline \multirow[t]{2}{*}{ Symptom } & \multicolumn{2}{|l|}{$\begin{array}{l}\text { Score questionnaire } \\
(\text { mean } \pm \mathrm{SE})\end{array}$} & \multirow[b]{2}{*}{ Difference } & \multirow{2}{*}{$\begin{array}{l}\text { Estimate }(\beta) \text { for energy } \\
{\text { intake }(\mathrm{kcal})^{\mathrm{a}}}^{(95 \% \mathrm{CI})}\end{array}$} \\
\hline & Comparison group & Patient group & & \\
\hline Pain & $1.6 \pm 0.13$ & $1.9 \pm 0.11$ & $0.3(-0.0 ; 0.5)$ & $\begin{array}{c}54.2 \\
(-2.8 ; 111.2)\end{array}$ \\
\hline Dry mouth & $1.3 \pm 0.15$ & $2.9 \pm 0.12$ & $1.6(1.3 ; 1.9)^{*}$ & $\begin{array}{c}-47.1 * \\
(-92.5 ;-1.8)\end{array}$ \\
\hline Depressed & $1.3 \pm 0.10$ & $1.6 \pm 0.08$ & $0.3(0.1 ; 0.5)^{*}$ & $\begin{array}{c}5.4 \\
(-68.4 ; 79.1)\end{array}$ \\
\hline Thick saliva & $1.1 \pm 0.12$ & $1.9 \pm 0.10$ & $0.8(0.6 ; 1.1)^{*}$ & $\begin{array}{c}-56.3 \\
(-114.1 ; 1.5)\end{array}$ \\
\hline Diarrhoea & $1.0 \pm 0.09$ & $1.5 \pm 0.07$ & $0.5(0.2 ; 0.6)^{*}$ & $\begin{array}{c}-3.1 \\
(-75.9 ; 69.6)\end{array}$ \\
\hline Sore mouth & $1.3 \pm 0.13$ & $2.2 \pm 0.11$ & $0.9(0.7 ; 1.2)^{*}$ & $\begin{array}{c}-35.7 \\
(-86.0 ; 14.6)\end{array}$ \\
\hline Lack of energy & $1.6 \pm 0.14$ & $3.3 \pm 0.12$ & $1.7(1.5 ; 2.0)^{*}$ & $\begin{array}{c}-55.5^{*} \\
(-99.0 ;-12.1)\end{array}$ \\
\hline Nausea & $1.1 \pm 0.10$ & $1.7 \pm 0.08$ & $0.6(0.4 ; 0.8)^{*}$ & $\begin{array}{c}-77.7^{*} \\
(-139.4 ;-16.0)\end{array}$ \\
\hline Difficulty chewing & $1.1 \pm 0.09$ & $1.5 \pm 0.07$ & $0.4(0.2 ; 0.6)^{*}$ & $\begin{array}{c}-102.6^{*} \\
(-180.3 ;-24.9)\end{array}$ \\
\hline Difficulty swallowing & $1.1 \pm 0.08$ & $1.5 \pm 0.06$ & $0.4(0.2 ; 0.6)^{*}$ & $\begin{array}{c}-33.6 \\
(-117.1 ; 49.8)\end{array}$ \\
\hline Constipation $^{\mathrm{b}}$ & $1.3 \pm 0.12$ & $1.8 \pm 0.09$ & $0.5(0.2 ; 0.7)^{*}$ & \\
\hline Constipation control & & & & $\begin{array}{c}-103.3 \\
(-228.8 ; 22.3)\end{array}$ \\
\hline Constipation patient & & & & $\begin{array}{c}42.1 \\
(-34.1 ; 118.5)\end{array}$ \\
\hline Anxiety $^{b}$ & $1.2 \pm 0.08$ & $1.5 \pm 0.07$ & $0.3(0.1 ; 0.4)^{*}$ & \\
\hline Anxiety control & & & & $\begin{array}{c}-208.7^{*} \\
(-384.1 ;-33.3)\end{array}$ \\
\hline Anxiety patient & & & & $\begin{array}{c}83.1 \\
(-18.2 ; 184.5)\end{array}$ \\
\hline Vomiting $^{\mathrm{c}}$ & $1.0 \pm 0.04$ & $1.1 \pm 0.03$ & $0.04(-0.04 ; 0.12)$ & \\
\hline
\end{tabular}

${ }^{\text {a }}$ Adjusted for age, BMI, education level, smoking status

${ }^{\mathrm{b}}$ For anxiety and constipation significant interactions were found on the association with energy intake, therefore stratified results are shown

${ }^{\mathrm{c}}$ For vomiting only one control and three patients reported a score of 2 or higher on the questionnaire, therefore this symptom was not analysed for the association with energy intake the patient group than the comparison group at the start of our study. As persons with higher BMI tend to underestimate dietary intake, the patient group may have underestimated their intake, explaining the difference in intake between women with breast cancer and women without cancer observed during chemotherapy. However, habitual intake was similar between patients and the comparison group at baseline and analyses were adjusted for BMI. Therefore, we do not expect that differential reporting substantially influenced our results.
In conclusion, our study is the largest study to date showing that breast cancer patients have a lower dietary intake during chemotherapy, which is expressed in a lower intake of specific food groups. The lower intake was associated with specific symptoms. These finding can guide clinicians to inform patients about the potential impact of chemotherapy and related symptoms on dietary intake and to ensure an adequate intake of energy and nutrients during chemotherapy. 
Acknowledgements We thank all participants for their time to participate in the study. Furthermore, we thank the staff of the following hospitals that helped recruiting the participants: Ziekenhuis Gelderse Vallei, Maxima Medisch Centrum, Reinier de Graaf Ziekenhuis, Onze Lieve Vrouwen Gasthuis, Amphia Ziekenhuis, Canisius Wilhelmina Ziekenhuis, Radboud Universitair Medisch Centrum, Alexander Monro Ziekenhuis, St. Antonius Ziekenhuis, St. Anna Ziekenhuis and Flevoziekenhuis. Also, we would like to thank the Pauline Claessen, Renske Geers, Lisette Kamps, Celine Kelfkens, Liesbeth Posthuma, Evelien Dik and Vera Hemink for their help during data collection and data cleaning.

\section{Compliance with ethical standards}

Funding This study was funded by the Dutch Cancer Society (grant numbers UW2011-4987 and UW2011-5268) and TI Food and Nutrition, a public-private partnership on precompetitive research in food and nutrition. The public partners are responsible for the study design, data collection and analysis, decision to publish and preparation of the manuscript. The private partners have contributed to the project through regular discussion.

Conflict of interest The authors declare that they have no conflict of interest.

Ethical approval All procedures performed in studies involving human participants were in accordance with the ethical standards of the institutional and/or national research committee and with the 1964 Helsinki declaration and its later amendments or comparable ethical standards.

Informed consent Informed consent was obtained from all individual participants included in the study.

Open Access This article is distributed under the terms of the Creative Commons Attribution-NonCommercial 4.0 International License (http:// creativecommons.org/licenses/by-nc/4.0/), which permits any noncommercial use, distribution, and reproduction in any medium, provided you give appropriate credit to the original author(s) and the source, provide a link to the Creative Commons license, and indicate if changes were made.

\section{References}

1. Sukel MPP, van de Poll-Franse LV, Nieuwenhuijzen GAP, Vreugdenhil G, Herings RMC, Coebergh JWW 1846-1854 Voogd AC (2008) Substantial increase in the use of adjuvant systemic treatment for early stage breast cancer reflects changes in guidelines in the period 1990-2006 in the southeastern Netherlands. European Journal of Cancer 44

2. Hall E, Cameron D, Waters R, Barrett-Lee P, Ellis P, Russell S, Bliss JM, Hopwood P (2014) Comparison of patient reported quality of life and impact of treatment side effects experienced with a taxanecontaining regimen and standard anthracycline based chemotherapy for early breast cancer: 6 year results from the UK TACT trial (CRUK/01/001). Eur J Cancer 50:2375-2389

3. Kayl AE, Meyers CA (2006) Side-effects of chemotherapy and quality of life in ovarian and breast cancer patients. Curr Opin Obstet Gynecol 18:24-28

4. Kubrak C, Olson K, Baracos VE (2013) The head and neck symptom checklist $\odot$ : an instrument to evaluate nutrition impact symptoms effect on energy intake and weight loss. Support Care Cancer 21:3127-3136

5. Farhangfar A, Makarewicz M, Ghosh S, Jha N, Scrimger R, Gramlich L, Baracos V (2014) Nutrition impact symptoms in a population cohort of head and neck cancer patients: multivariate regression analysis of symptoms on oral intake, weight loss and survival. Oral Oncol 50:877-883

6. Grindel CG, Cahill CA, Walker M (1989) Food intake of women with breast cancer during their first six month of chemotherapy. Oncol Nurs Forum 16:401-407

7. Custódio IDD, Marinho EDC, Gontijo CA, Pereira TSS, Paiva CE, De Maia YCP (2016) Impact of chemotherapy on diet and nutritional status of women with breast cancer: A prospective study. PLoS ONE 11

8. Demark-Wahnefried W, Rimer BK, Winer EP (1997) Weight gain in women diagnosed with breast cancer. J Am Diet Assoc 97:519-526

9. Demark-Wahnefried W, Peterson BL, Winer EP, Marks L, Aziz N, Marcom PK, Blackwell K, Rimer BK (2001) Changes in weight, body composition, and factors influencing energy balance among premenopausal breast cancer patients receiving adjuvant chemotherapy. J Clin Oncol 19:2381-2389

10. Harvie MN, Campbell IT, Baildam A, Howell A (2004) Energy balance in early breast cancer patients receiving adjuvant chemotherapy. Breast Cancer Res Treat 83:201-210

11. Del Rio G, Zironi S, Valeriani L, Menozzi R, Bondi M, Bertolini M, Piccinini L, Banzi MC, Federico M (2002) Weight gain in women with breast cancer treated with adjuvant cyclophosphomide, methotrexate and 5-fluorouracil. Analysis of resting energy expenditure and body composition. Breast Cancer Res Treat 73:267-273

12. Mardas M, Mądry R, Stelmach-Mardas M (2016) Dietary intake variability in the cycle of cytotoxic chemotherapy. Support Care Cancer 24:2619-2625

13. Makari-Judson G, Braun B, Joseph Jerry D, Mertens WC (2014) Weight gain following breast cancer diagnosis: implication and proposed mechanisms. World Journal of Clinical Oncology 5: 272-282

14. Vance V, Mourtzakis M, McCargar L, Hanning R (2011) Weight gain in breast cancer survivors: prevalence, pattern and health consequences. Obes Rev 12:282-294

15. Kwok A, Palermo C, Boltong A (2015) Dietary experiences and support needs of women who gain weight following chemotherapy for breast cancer. Support Care Cancer 23:1561-1568

16. Harrison JD, Young JM, Price MA, Butow PN, Solomon MJ (2009) What are the unmet supportive care needs of people with cancer? A systematic review. Support Care Cancer 17:1117-1128

17. Siebelink E, Geelen A, De Vries JHM (2011) Self-reported energy intake by FFQ compared with actual energy intake to maintain body weight in 516 adults. Brit J Nutr 106:274-281

18. Streppel MT, De Vries JH, Meijboom S, Beekman M, De Craen AJ, Slagboom PE, Feskens EJ (2013) Relative validity of the food frequency questionnaire used to assess dietary intake in the Leiden Longevity Study. Nutr J 12

19. RIVM (2013) NEVO-tabel. Nederlands Voedingsstoffenbestand Bilthoven

20. Mathey MFAM, De Jong N, De Groot CPGM, De Graaf C, Van Staveren WA (2001) Assessing appetite in Dutch elderly with the appetite, hunger and sensory perception (AHSP) questionnaire. Journal of Nutrition, Health and Aging 5:22-26

21. Research. WCRFAIfC (2010) Continuous Update Project Report. Food, Nutrition, Physical Activity, and the Prevention of Breast Cancer. In: Editor (ed)^(eds) Book Continuous Update Project Report. Food, Nutrition, Physical Activity, and the Prevention of Breast Cancer, City

22. Demark-Wahnefried W, Aziz NM, Rowland JH, Pinto BM (2005) Riding the crest of the teachable moment: promoting long-term health after the diagnosis of cancer. J Clin Oncol 23:5814-5830 
23. Boltong A, Aranda S, Keast R, Wynne R, Francis PA, Chirgwin J, Gough K (2014) A prospective cohort study of the effects of adjuvant breast cancer chemotherapy on taste function, food liking, appetite and associated nutritional outcomes. PLoS One:9

24. McCrickerd K, Forde CG (2016) Sensory influences on food intake control: moving beyond palatability. Obes Rev 17:18-29

25. Haxel BR, Bertz-Duffy S, Fruth K, Letzel S, Mann WJ, Muttray A (2012) Comparison of subjective olfaction ratings in patients with and without olfactory disorders. J Laryngol Otol 126:692-697

26. Wagland R, Richardson A, Ewings S, Armes J, Lennan E, Hankins M, Griffiths P (2016) Prevalence of cancer chemotherapy-related problems, their relation to health-related quality of life and associated supportive care: a cross-sectional survey. Support Care Cancer 24:4901-4911

27. Boltong A, Keast R (2012) The influence of chemotherapy on taste perception and food hedonics: a systematic review. Cancer Treat Rev 38:152-163
28. Steinbach S, Hummel T, Böhner C, Berktold S, Hundt W, Kriner M, Heinrich P, Sommer H, Hanusch C, Prechtl A, Schmidt B, Bauerfeind I, Seck K, Jacobs VR, Schmalfeldt B, Harbeck N (2009) Qualitative and quantitative assessment of taste and smell changes in patients undergoing chemotherapy for breast cancer or gynecologic malignancies. J Clin Oncol 27:1899-1905

29. Irwin ML, Crumley D, McTiernan A, Bernstein L, Baumgartner R, Gilliland FD, Kriska A, Ballard-Barbash R (2003) Physical activity levels before and after a diagnosis of breast carcinoma: the health, eating, activity, and lifestyle (HEAL) study. Cancer 97:1746-1757

30. Trijsburg L, Geelen A, Hollman PCH, Hulshof PJM, Feskens EJM, van't Veer P, Boshuizen HC, de Vries JHM (2016) BMI was found to be a consistent determinant related to misreporting of energy, protein and potassium intake using self-report and duplicate portion methods. Public Health Nutr 1-10 